\title{
8
}
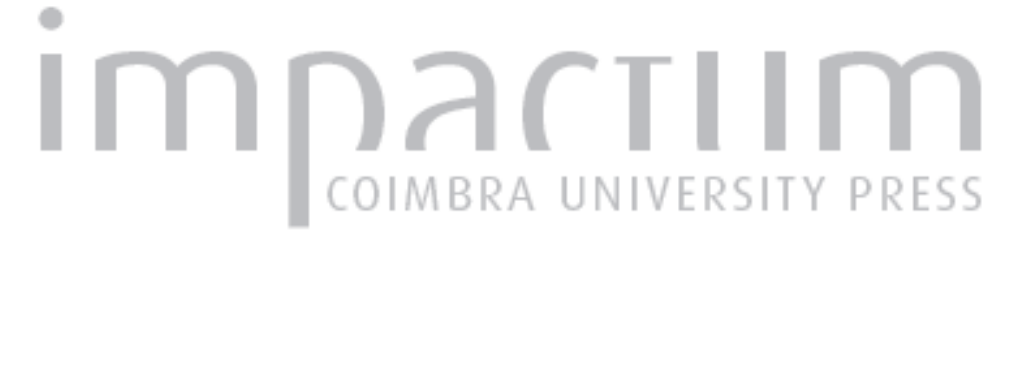

\section{[Recensão a] Miguel Ángel Ladero Quesada - Ejércitos y armadas de los Reyes Católicos - Nápoles y el Rosellón (1494-1504)}

Autor(es): $\quad$ Encarnação, Marcelo

Publicado por: $\begin{aligned} & \text { Faculdade de Letras da Universidade de Coimbra, Instituto de História } \\ & \text { Económica e Social }\end{aligned}$

URL

persistente:

URI:http://hdl.handle.net/10316.2/28384

DOI: $\quad$ DOI:http://dx.doi.org/10.14195/0870-4147_43_18

Accessed : $\quad$ 26-Apr-2023 03:28:44

A navegação consulta e descarregamento dos títulos inseridos nas Bibliotecas Digitais UC Digitalis, UC Pombalina e UC Impactum, pressupõem a aceitação plena e sem reservas dos Termos e Condições de Uso destas Bibliotecas Digitais, disponíveis em https://digitalis.uc.pt/pt-pt/termos.

Conforme exposto nos referidos Termos e Condições de Uso, o descarregamento de títulos de acesso restrito requer uma licença válida de autorização devendo o utilizador aceder ao(s) documento(s) a partir de um endereço de IP da instituição detentora da supramencionada licença.

Ao utilizador é apenas permitido o descarregamento para uso pessoal, pelo que o emprego do(s) título(s) descarregado(s) para outro fim, designadamente comercial, carece de autorização do respetivo autor ou editor da obra.

Na medida em que todas as obras da UC Digitalis se encontram protegidas pelo Código do Direito de Autor e Direitos Conexos e demais legislação aplicável, toda a cópia, parcial ou total, deste documento, nos casos em que é legalmente admitida, deverá conter ou fazer-se acompanhar por este aviso. 



\section{Miguel Ángel Ladero Quesada, Ejércitos y armadas de los Reyes Católicos} - Nápoles y el Rosellón (1494-1504), Madrid: Real Academia de la Historia, 2010, 861 p.

Embora os meandros da política interna e diplomática da última década dos Reis Católicos sejam já bem conhecidos, o mesmo não se verifica no que às campanhas militares do Rossilhão e de Itália diz respeito. Estas são sempre vistas na perspectiva do pós-conquista de Granada e configurando a evolução para uma estrutura militar moderna. Com respeito a estas campanhas, havia uma lacuna ao nível do seu conhecimento militar rigoroso, em parte porque apenas há cronistas oficiais até 1492, motivo pelo qual a utilização de crónicas e de memoriais mais tardios precisava de ser completada com o recurso aos documentos. Neste livro, o objetivo do autor é, justamente, «mejorar el saber histórico (...) [e] ofrecer explicaciones coherentes y lo más completas que sea posible sobre asuntos estudiados de forma monográfica, de manera que los nuevos conocimientos obtenidos y las perspectivas abiertas sean también ayuda para otras investigaciones» (p. XIV).

Neste sentido, Miguel Ángel Ladero Quesada usa exaustivamente documentos de carácter financeiro para complementar as fontes cronísticas e para nos proporcionar uma visão global mais próxima da realidade hispânica de finais do século XV e inícios do XVI. Foram analisados pagamentos de tropas - permanentes e contratadas -, armadas, abastecimento de víveres e outros bens necessários ao bom funcionamento do exército, armas, correios, empréstimos, câmbios e a dízima eclesiástica. O autor utilizou principalmente documentos inéditos espanhóis, mas não deixou de recorrer a outra documentação espanhola, francesa e italiana editada, a qual serve de complemento às crónicas, às memórias e a outras fontes dos séculos XVI a XVIII.

O estudo editado pela Real Academia de la Historia é um casamento feliz entre a averiguação dos aspetos financeiros e tributários, por um lado, e a análise da política e da guerra, por outro, apresentando porém uma perspetiva mais política do que militar, até porque as batalhas de que o autor nos dá conta são pouco mais do que meras referências com indicação do número de efetivos e do respetivo resultado, como é o caso da batalha que opôs Espanhóis a Franceses no campo de Seminara ou La Gioia (p. 92), ou o caso da batalha de Ceriñola (p. 94).

O resultado destas opções é uma obra dividida em três partes. A Primeira Parte corresponde a uma generosa contextualização política, desde a subida ao poder de Isabel e Fernando até à redução dos efetivos militares, que chega com o fim das campanhas em Itália. Neste macro cenário, o autor identifica 
três grandes momentos: o acesso ao poder, entre 1468 e 1479; a reorganização política e a conquista de Granada, entre 1480 e 1492, reconhecendo Ladero Quesada este ano como sendo decisivo, devido à conquista de Granada, à expulsão dos judeus e ao acordo estabelecido com um nome que ficaria famoso: Cristóvão Colombo; e um terceiro momento, correspondente ao último decénio de vida de Isabel, que equivale, grosso modo, a uma época de prosperidade. Nesta última síntese estão integrados, é claro, os conflitos galo-hispânicos do Rossilhão e em Nápoles (1495-1498 e 1500-1504), se bem que tenham existido algumas tréguas, as quais nem sempre vigoravam em todas as fronteiras. $\mathrm{O}$ autor explicita como, através de vicissitudes várias, Espanha e França assinaram o tratado de Chambord-Granada (em novembro de 1500), no qual acordavam a repartição do reino de Nápoles. Estiveram mesmo aliadas contra a ameaça muçulmana, uma vez que suspeitaram que Nápoles não hesitaria em pedir a ajuda dos Otomanos. A rutura surge com incidentes junto da praça militar de Atripalda, em Basilicata, e os roubos de gado a partir de junho de 1502 . Assim, as hostilidades iniciaram-se a 13 de setembro de 1502. Os Espanhóis permaneceram à defesa, até porque enfrentavam tropas mais numerosas, e os Franceses tiveram de reduzir-se a ações de bloqueio, sendo mal sucedidos nos seus intentos navais contra Barletta e Tarento. Entrava-se, assim, na segunda guerra.

Poderíamos pensar que, feita a retrospetiva política, o especialista em finanças nos daria um relato muito técnico de contas, com parcelas e somatórios extraídos dos documentos consultados. Tal não acontece e a Segunda Parte principia com o elenco dos meios e dos recursos militares necessários para fazer a guerra no final do século XV: cavalaria das Guardas Reales e da Hermandad; vassalos recebendo um estipêndio (chamados vassalos de acostamiento); nobres e Ordens Militares; milícias concelhias e a sua transição para a infantaria moderna; e, como não podia deixar de ser, a artilharia. Além disso, a defesa estática do território, através das fortalezas, as armas utilizadas pela soldadesca e o abastecimento dos soldados e das armadas, bem como a definição das mesmas, completam esta Segunda Parte, na qual o autor generosamente inclui os valores consultados nos documentos, tornando a reconstrução do passado numa história harmoniosa.

Se a segunda secção do livro é dedicada ao cenário pirenaico do Rossilhão, a Terceira Parte integra as guerras de Nápoles, nas quais as armadas tiveram um papel preponderante. A obra termina com um Apêndice riquíssimo, no qual o autor organiza os dados da fazenda pelas zonas geográficas em causa, por datas, e onde, seguindo estes dois critérios, vai arrolando tudo o que diz respeito à guerra. 
Financiar campanhas militares desta envergadura sem deitar o país a perder, vencê-las e ainda operacionalizar a transição para a guerra moderna, foi um processo estrutural que começou com a conquista de Granada e que terminou com a vitória nas guerras de Nápoles. Entre várias novidades, e só para citar dois exemplos, Ladero Quesada assinala a presença de «peones a la çuyça» (p. 215) e salienta que as «capitanias están ya agrupadas en coronelías, esto es formando regimientos, cosa que antes no había ocurrido» (p.454). Não obstante esta evolução, os Católicos tiveram de enfrentar grandes dificuldades, tais como: atrasos nos pagamentos (às vezes por mais de um ano); desvalorização pelo câmbio, registando o autor que «nunca los naçidos hisieron tanta guerra syn dinero y syn ser pagados tantos días» (p. 387); e as consequentes deserções. Porém, Isabel e Fernando superaram com êxito estes obstáculos, principalmente porque tinham uma política interna controlada e estável. Ainda assim, os gastos muito avultados, os quais superaram os nove anos da guerra contra Granada, exigiram recursos ordinários e extraordinários, num total de dezassete proveniências diferentes investigadas por Miguel Ángel Ladero Quesada. Conclui o autor que, embora haja a defesa de um objetivo comum às coroas de Castela e Aragão, cerca de $85 \%$ dos recursos empregues para financiar a guerra, seja no pagamento das tropas, no aluguer de carraças, ou na (re)construção da fortaleza de Salses (destruída pelos Franceses em Outubro de 1496), só para dar alguns exemplos, partiu da coroa da Castela, bem como a maior parte dos efetivos militares e navais utilizados na defesa de interesses comuns.

Apesar da sua análise dominantemente estrutural, Ladero Quesada presta também muita atenção ao papel de indivíduos, como é o caso de Hernando de Zafra, secretário dos Reis Católicos; de Alonso de Morales, tesoureiro do extraordinário; e de Juan de la Torre, pagador das Guardas Reales e de outras tropas permanentes a soldo dos Reis Católicos. O cuidado com estas figuras tanto permite associá-las à Fazenda como às empresas militares, detendo-se o autor em nomes como: Galcerán de Requesens, conde de Trevento e capitão geral da primeira armada, em 1495; Gonzalo Fernández de Córdoba, Gran Capitán; e Don Luis Portocarrero, comandante da expedição de socorro de 1503. Algumas das manobras levadas a cabo requereram uma logística impressionante, estando o teatro de operações a centenas de quilómetros, um facto que causava algum desconforto e insegurança a Isabel e a Fernando. Ladero Quesada documenta-nos esses receios recorrendo às numerosas missivas que os Reis Católicos, habituados a superintender pessoalmente as campanhas militares, enviaram aos responsáveis no terreno pelas guerras italianas.

Face ao exposto, o contributo deste novo livro do reputado investigador espanhol é decisivo. Através das relações dos pagamentos, podemos identificar 
uma miríade de perguntas que agora passam a ter resposta: quantidade, proveniência genealógica e geográfica, tipologia e cadeia de comando dos soldados (incluindo os mercenários); organização social do exército (milícias concelhias, nobres, Ordens Militares, entre outros); número de cavalos de combate e de bestas de carga; armamento ofensivo e defensivo utilizado; víveres consumidos por homens e por animais (trigo, cevada e vinho); recurso a artilharia e a munições (tipologia, quantidade, mestres artilheiros estrangeiros e castelhanos); tipologia, quantidade, proveniência, estatuto jurídico e pilotos das embarcações utilizadas; bandeiras e divisas usadas pelos homens; e, claro está, a configuração que estas forças assumiam no terreno, efetuando o autor algumas comparações entre as duas guerras em apreço. Por último, Ladero Quesada apresenta-nos uma estimativa rigorosa do custo total da guerra no Rossilhão e em Nápoles, que ascendeu aproximadamente a 2.079.000.000 maravedis.

Em conclusão, estamos perante uma obra que se saúda vivamente, uma vez que apresenta um contributo decisivo para o estado do conhecimento atual das guerras no Rossilhão e em Itália, no tempo dos Reis Católicos.

\section{Marcelo Encarnação}

Doutorando em História (FLUP) e membro do CITCEM

Adélio Fernando Abreu, D. Américo Ferreira dos Santos Silva, Bispo do Porto (1871-1899), Igreja e Sociedade no Porto no Fim do século XIX. Porto: Universidade Católica Portuguesa, Centro Regional do Porto, Faculdade de Teologia, 2010.

Adélio Abreu ao estudar o bispo do Porto, D Américo Ferreira dos Santos Silva, contempla, numa análise rigorosa, as relações entre a Igreja e o Estado durante a implantação do liberalismo em Portugal. O quadro legislativo que vigorou durante a governação do bispo do Porto insere-se no crescente regalismo do Estado sublinhado pela supressão dos dízimos, abolição do foro eclesiástico, eliminação dos padroados eclesiásticos e laicos, extinção das ordens religiosas e nacionalização dos bens da Igreja: o rei tornou-se o único padroeiro. Rapidamente, este quadro determinou as relações com a Santa Sé que encontraram grandes tensões e, mesmo, conflitos.

D. Américo Ferreira dos Santos Silva nasceu no Porto, a 16 de Janeiro de 1830 e era oriundo de uma família de comerciantes da alta burguesia ligada à banca e a companhias comerciais. O pai, sócio da Associação Comercial do Porto, foi deputado nas legislaturas de 1842 a 1846 e pertenceu à maçonaria. 